\title{
Diagnostic and prognostic value of serum C-reactive protein in heart failure with preserved ejection fraction: a systematic review and meta-analysis
}

\author{
Ishan Lakhani ${ }^{1} \cdot$ Michelle Vangi Wong ${ }^{1} \cdot$ Joshua Kai Fung Hung ${ }^{1} \cdot$ Mengqi Gong $^{2} \cdot$ Khalid Bin Waleed $^{3} \cdot$ Yunlong Xia $^{3}$. \\ Sharen Lee ${ }^{1}$. Leonardo Roever ${ }^{4}$. Tong Liu ${ }^{2} \cdot$ Gary Tse $^{2,3,5} \cdot$ Keith Sai Kit Leung $^{6}$ (D) Ka Hou Christien Li $^{7}$
}

Published online: 6 February 2020

(C) The Author(s) 2020

\begin{abstract}
Heart failure (HF) is a major epidemic with rising morbidity and mortality rates that encumber global healthcare systems. While some studies have demonstrated the value of CRP in predicting (i) the development of HFpEF and (ii) long-term clinical outcomes in HFpEF patients, others have shown no such correlation. As a result, we conducted the following systematic review and meta-analysis to assess both the diagnostic and prognostic role of CRP in HFpEF. PubMed and Embase were searched for studies that assess the relationship between CRP and HFpEF using the following search terms: (((C-reactive protein) AND ((preserved ejection fraction) OR (diastolic heart failure))). The search period was from the start of database to August 6, 2019, with no language restrictions. A total of 312 and 233 studies were obtained from PubMed and Embase respectively, from which 19 studies were included. Our meta-analysis demonstrated the value of a high CRP in predicting the development of not only new onset HFpEF (HR: $1.08 ; 95 \%$ CI: $1.00-1.16 ; P=0.04 ; I^{2}=22 \%$ ), but also an increased risk of cardiovascular mortality when used as a categorical (HR: 2.52 ; $95 \%$ CI: $1.61-3.96 ; P<0.0001 ; I^{2}=19 \%$ ) or a continuous variable (HR: $1.24 ; 95 \%$ CI: 1.04 $1.47 ; P=0.01 ; I^{2}=28 \%$ ), as well as all-cause mortality when used as a categorical (HR: $1.78 ; 95 \%$ CI: $1.53-2.06 ; P<0.00001$; $I^{2}=0 \%$ ) or a continuous variable: (HR: $1.06 ; 95 \%$ CI: $1.02-1.06 ; P=0.003 ; I^{2}=61 \%$ ) in HFpEF patients. CRP can be used as a biomarker to predict the development of HFpEF and long-term clinical outcomes in HFpEF patients, in turn justifying its use as a simple, accessible parameter to guide clinical management in this patient population. However, more prospective studies are still required to not only explore the utility and dynamicity of CRP in HFpEF but also to determine whether risk stratification algorithms incorporating CRP actually provide a material benefit in improving patient prognosis.
\end{abstract}

Keywords C-reactive protein $\cdot$ Diastolic heart failure $\cdot \mathrm{HFpEF} \cdot$ Meta-analysis

Electronic supplementary material The online version of this article (https://doi.org/10.1007/s10741-020-09927-x) contains supplementary material, which is available to authorized users.

Keith Sai Kit Leung

180006720@aston.ac.uk

Ka Hou Christien Li

lijiahao218@gmail.com

1 Li Ka Shing Institute of Health Sciences, Faculty of Medicine, Chinese University of Hong Kong, Hong Kong, SAR, People's Republic of China

2 Tianjin Key Laboratory of Ionic-Molecular Function of Cardiovascular disease, Department of Cardiology, Tianjin Institute of Cardiology, Second Hospital of Tianjin Medical University, Tianjin 300211, People's Republic of China
3 Department of Cardiovascular Medicine, The First Affiliated Hospital of Dalian Medical University, Dalian, China

4 Department of Clinical Research, Federal University of Uberlândia, Uberlândia, Brazil

5 Xiamen Cardiovascular Hospital, Xiamen University, Xiamen, Fujian, People's Republic of China

6 Aston Medical School, Aston University, Birmingham, UK

Wirral University Teaching Hospital NHS Foundation Trust, Arrowe Park Hospital, Arrowe Park Rd, Birkenhead, Wirral CH49 5PE, UK 


\section{Introduction}

Heart failure (HF) is a major epidemic with rising morbidity and mortality rates that encumber global healthcare systems. The 2016 European Society of Cardiology Guidelines denotes three classes of HF, stratified primarily according to ejection fraction: (i) HF with reduced ejection fraction (HFrEF), wherein $\mathrm{EF}$ in less than $40 \%$; (ii) $\mathrm{HF}$ with midrange ejection fraction (HFmrEF), wherein EF is between 40 and 50\%; (iii) $\mathrm{HF}$ with preserved ejection fraction (HFpEF), wherein $\mathrm{EF}$ is greater than $50 \%$ [1]. Although an abundance of evidence exists detailing the epidemiology, pathophysiology, and optimal treatment strategies for HFrEF, there much unknown pertaining to its counterpart, $\mathrm{HFpEF}$.

The pathogenesis of both HFrEF and HFpEF differ, and as such, therapies proven to be effective for HFrEF have often failed to yield the same favorable outcomes in HFpEF cohorts. One of the suggested mechanisms contributing to the development of HFpEF is a systemic inflammatory state that adversely affects cardiomyocyte function on a molecular level. This inflammatory milieu is characterized by an elevation in the serum levels of various biomarkers [2], one of which is Creactive protein (CRP): an acute phase protein produced by hepatocytes in a reactive response to inflammation [3].

Many investigations have analyzed the use of CRP as a biomarker to predict not only the development of HFpEF but also long-term clinical outcomes that may occur in HFpEF patients. However, while some studies have demonstrated a relationship between CRP and HFpEF, others have shown no such correlation. As a result, we conducted the following systematic review and meta-analysis to assess both the diagnostic and prognostic role of CRP in HFpEF.

\section{Methods}

\section{Search strategy, inclusion, and exclusion criteria}

This systematic review and meta-analysis was performed according to the Preferred Reporting Items for Systematic Reviews and Meta-Analyses (PRISMA) statement [4]. PubMed and Embase were searched up to August 6, 2019, with no language restrictions, for studies assessing the relationship between CRP and HFpEF development as well as outcomes in HFpEF patients. The following search terms were used: (C-reactive protein) AND ((preserved ejection fraction) OR (diastolic heart failure)). The inclusion criteria was as follows: (i) the study was a prospective or retrospective cohort study in humans and (ii) hazard ratios for risk of new onset $\mathrm{HFpEF}$ as well as prognostic outcomes including cardiovascular (CV) mortality, long-term CV outcomes, and all-cause mortality were reported in the published data.
The Newcastle-Ottawa Quality Assessment Scale (NOS) was used for quality assessment of the included studies. The NOS point score system evaluated the categories of study participant selection, comparability of the results, and quality of the outcomes. The following characteristics were assessed: (a) representativeness of the exposed cohort, (b) selection of the non-exposed cohort, (c) ascertainment of exposure, (d) demonstration that outcome of interest was not present at the start of study, (e) comparability of cohorts based on study design or analysis, (f) assessment of outcomes; (g) follow-up periods that were sufficiently long for outcomes to occur, and (h) adequacy of follow-up of cohorts. This scale ranged from zero to nine stars, which indicated that studies were graded as poor quality if the score was $<5$, fair if the score was 5 to 7 , and good if the score was $>8$.

\section{Data extraction and statistical analysis}

Data from the different studies were entered in pre-designed spreadsheets using Microsoft Excel. All abstracts were retrieved as complete manuscripts and assessed against the inclusion criteria. The data extracted include: (i) publication details: last name of first author, publication year, and locations; (ii) study design; (iii) follow-up duration; (iv) endpoint(s); (v) quality score; and (vii) characteristics of the population including sample size, gender, age, and number of subjects. Two reviewers (IL and KL) reviewed each included study independently. Disagreements were resolved by adjudication with input from a third reviewer (GT).

Statistical analysis was performed using the Comprehensive Meta-Analysis Software (Version 3). Heterogeneity between studies was determined using Cochran's $Q$ value, the weighted sum of squared differences between individual study effects and the pooled effect across studies, and the $I^{2}$ statistic determined from the standard chisquare test, which describes the proportion of total varianceexplained heterogeneity. $I^{2}>50 \%$ was considered to reflect significant statistical heterogeneity. A fixed effects model was used if $I^{2}<50 \%$; otherwise, the random effects model using the inverse variance heterogeneity method was used. To identify the source of the heterogeneity, a sensitivity analysis using the leave-one-out method was performed. Funnel plots, Begg and Mazumdar rank correlation test, and Egger's test were also used to assess for possible publication bias.

\section{Results}

Figure 1 demonstrated the study identification and selection process. Three hundred and twelve and 233 studies were obtained from PubMed and Embase respectively, from which a total of 19 studies satisfied the inclusion criteria. The details of the NOS quality assessment for the included cohort studies are 
Fig. 1 Study identification and selection process from PubMed and Embase

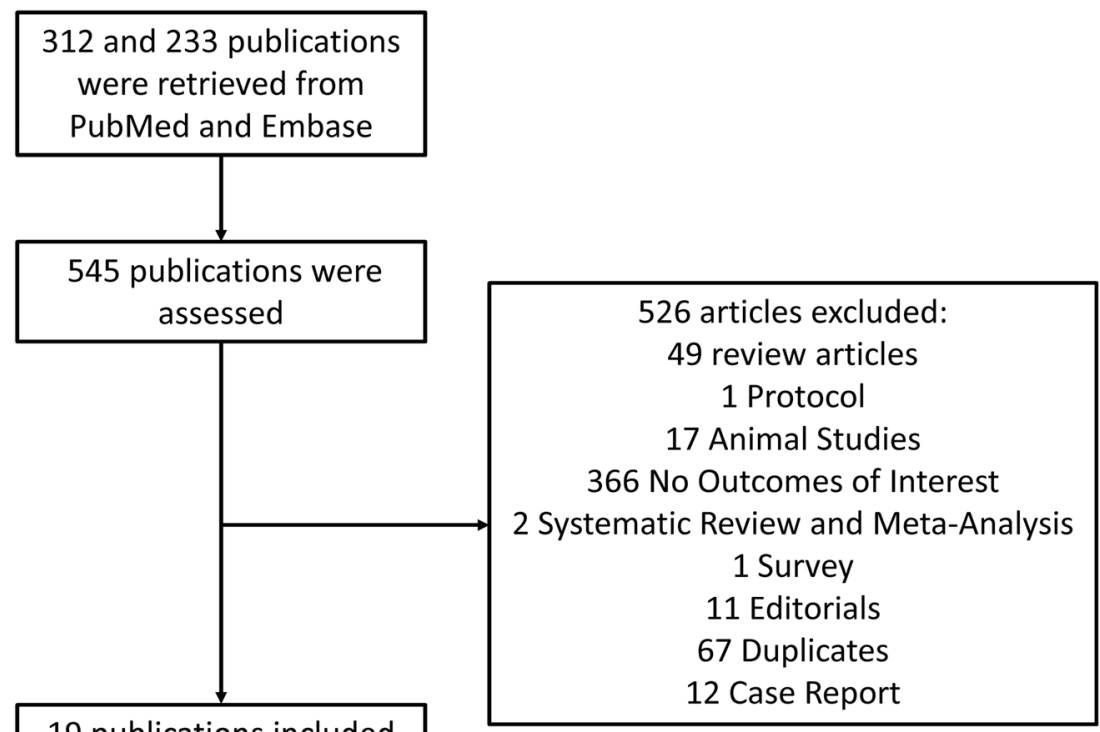

19 publications included

in the final meta-analysis shown in Supplementary Table 1. Baseline characteristics of these studies and of the study populations are shown in Table 1. A total of 51,196 patients with a mean age of 61.1 \pm 13.9 years were included. Fifty percent of the population was male, and the mean follow-up period was 120 months.

\section{Diagnostic value of CRP in predicting new onset HFpEF}

Eight studies [5-9] examined the correlation between CRP as a continuous variable and the risk of new onset HFpEF (Fig. 2a). Among these, De Boer et al. examined the risk of HFpEF development in four longitudinal cohorts (the Framingham Heart Study (FHS); the Cardiovascular Health Study (CHS); the Prevention of Renal and Vascular End-stage Disease (PREVEND) cohort; the Multi-Ethnic Study of Atherosclerosis (MESA)). Meta-analysis of the included studies using the independent associations reported in de Boer et al. revealed a significant relationship between CRP and HFpEF development (HR: 1.08; 95\% CI: 1.01-1.16; $P=$ $0.04 ; I^{2}=22 \%$ ). It should be noted that Brouwers et al. and Silverman et al. also assessed this relationship using the PREVEND and MESA cohorts, respectively, but did so using a larger sample size. As a result, in order to avoid potentially meta-analyzing overlapping populations a subset analysis was performed, with the findings of Browuers et al. (PREVEND Cohort) and Silverman et al. (MESA cohort) included and those of the PREVEND and MESA patients in de Boer et al. excluded (Fig. 2b). Subsequent meta-analysis in turn showed that a high CRP was still significantly associated with a $9 \%$ increase in the risk of new onset HFpEF, a result reported with a lower heterogeneity than that of the aforementioned (HR: 1.09; 95\% CI: $\left.1.01-1.18 ; P=0.04 ; I^{2}=0 \%\right)$.

\section{Prognostic value of CRP in predicting outcomes following HFpEF}

\section{Cardiovascular mortality}

Two studies [10, 11] examined the prognostic value of CRP as a categorical variable in predicting $\mathrm{CV}$ mortality in HFpEF patients (Fig. 3a). Subsequent meta-analysis revealed that a high CRP significantly predicted a greater than twofold increase in the risk of CV mortality (HR: 2.52 ; $95 \%$ CI: $1.61-$ 3.96; $\left.P<0.0001 ; I^{2}=19 \%\right)$. Furthermore, two additional studies [10, 12] also assessed this relationship but instead utilized CRP as a continuous variable (Fig. 3b). Of these two, only one reported a significant relationship. Metaanalysis of these studies indicated yet another significant, albeit smaller, association (HR: $1.24 ; 95 \% \mathrm{CI}: 1.05-1.47 ; P=$ $0.01 ; I^{2}=28 \%$ ).

\section{Cardiovascular outcomes}

A total of three studies [13-15] assessed the relationship between CRP as a categorical variable and the risk of long-term adverse CV outcomes (Fig. 4a). Chen et al. used a composite endpoint of CV death, myocardial infarction (MI), and unstable angina pectoris, while Vrsalović et al. and Sabatine et al. employed composite outcomes of MACE and CV death, MI, or stroke respectively. Two of these three studies were independently significant, and subsequent meta-analysis showed that a high CRP was in fact related to a greater risk of longterm adverse cardiovascular outcomes (HR: 1.55; 95\% CI: $\left.1.22-1.96 ; P<0.0003 ; I^{2}=37 \%\right)$. Two studies $[16,17]$ examined such a relationship by using CRP as a continuous variable (Fig. 4b). Both employed the same composite endpoint in 


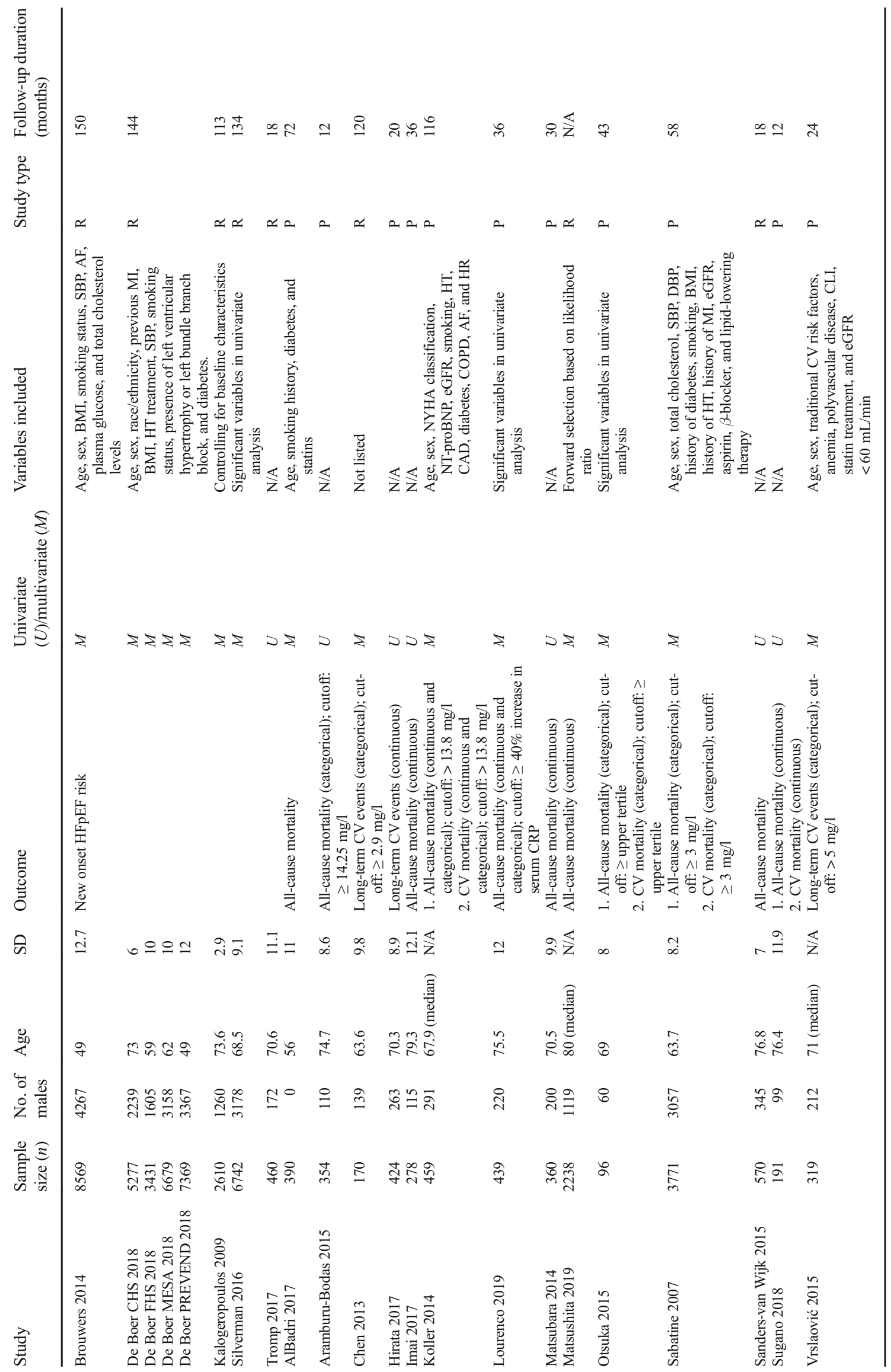


Fig. 2 High CRP as a continuous variable and risk of new onset HFpEF: a without the exclusion of overlapping cohorts; $\mathbf{b}$ with the exclusion of overlapping cohorts a) High CRP as a continuous variable and risk of new onset HFpEF

Study name
Brouwers 2014
de Boer CHS 2018
de Boer FHS 2018
de Boer MESA 2018
de Boer PREVEND 2018
Kalogeropoulos 2009
Silverman 2016
Tromp 2017

Statistics for each study

$\begin{array}{cccrr}\begin{array}{c}\text { Hazard } \\ \text { ratio }\end{array} & \begin{array}{c}\text { Lower } \\ \text { limit }\end{array} & \begin{array}{c}\text { Upper } \\ \text { limit }\end{array} & \text { z-Value } & \text { p-Value } \\ 1.180 & 0.730 & 1.909 & 0.675 & 0.500 \\ 1.080 & 0.958 & 1.217 & 1.259 & 0.208 \\ 0.950 & 0.729 & 1.238 & -0.379 & 0.704 \\ 1.250 & 1.009 & 1.549 & 2.042 & 0.041 \\ 0.820 & 0.640 & 1.050 & -1.571 & 0.116 \\ 1.150 & 0.971 & 1.362 & 1.621 & 0.105 \\ 1.170 & 0.931 & 1.471 & 1.344 & 0.179 \\ 1.000 & 0.770 & 1.299 & 0.000 & 1.000 \\ 1.079 & 1.005 & 1.159 & 2.086 & 0.037\end{array}$

Hazard ratio and $95 \% \mathrm{Cl}$

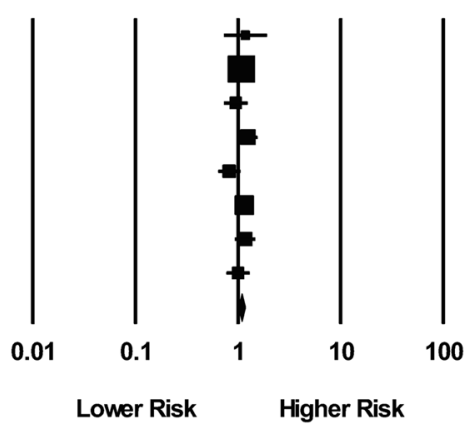

b) High CRP as a continuous variable and risk of new onset HFpEF with the exclusion of overlapping cohorts their investigations: CV death, MI, unstable angina pectoris, non-ischemic stroke, hospitalization for HF decompensation, and coronary revascularization. Meta-analysis of these studies, however, did not report a significant association (HR: 1.09; 95\% CI: $0.88-1.34 ; P=0.44 ; I^{2}=83 \%$ ).

\section{All-cause mortality}

Five studies $[10,11,14,18,19]$ investigated the correlation between CRP as a categorical variable and all-cause mortality in HFpEF patients (Fig. 5a). Meta-analysis of these studies showed that a high CRP predicted a $78 \%$ increase in the risk of all-cause mortality (HR: 1.78 ; 95\% CI: 1.53-2.06; $\left.P<0.00001 ; I^{2}=0 \%\right)$. Likewise, similar findings were demonstrated when employing CRP as a continuous variable (Fig. 5b). A total of seven studies [10, 12, 19-23] assessed this relationship, of which only four reported significant results. Subsequent meta-analysis of these studies, however, illustrated yet again that a high CRP as a continuous variable was significantly associated with an increased risk of all-cause mortality (HR: $1.06 ; 95 \%$ CI: $1.02-1.10 ; P=0.004 ; I^{2}=$ $61 \%)$.

\section{Sensitivity and bias analyses}

The results of sensitivity analysis performed by excluding one study at a time are shown in Supplementary Figure 1A to H. The results of publication bias are shown in Supplementary Figures $2 \mathrm{~A}$ to $\mathrm{E}$.

\section{Discussion}

The findings of this systematic review and meta-analysis are that CRP has both diagnostic value in predicting the risk of new onset HFpEF, as well as prognostic value in predicting cardiovascular outcomes and all-cause mortality following HFpEF development.

HFrEF and HFpEF are binary oppositions on the same disease spectrum. The mechanism of HFrEF is well understood, and primarily involves an initial insult that triggers myocardial injury as well as adverse remodeling, culminating in a reduction of cardiac output [24]. However, HFpEF instead represents a more complex syndrome comprised of a heterogeneous phenotype secondary to many different interacting pathophysiological processes [25]. As aforementioned, the 
Fig. 3 High CRP as a a categorical variable and risk of cardiovascular mortality; as a b continuous variable and risk of cardiovascular mortality

a) High CRP as a categorical variable and risk of cardiovascular mortality

Statistics for each study

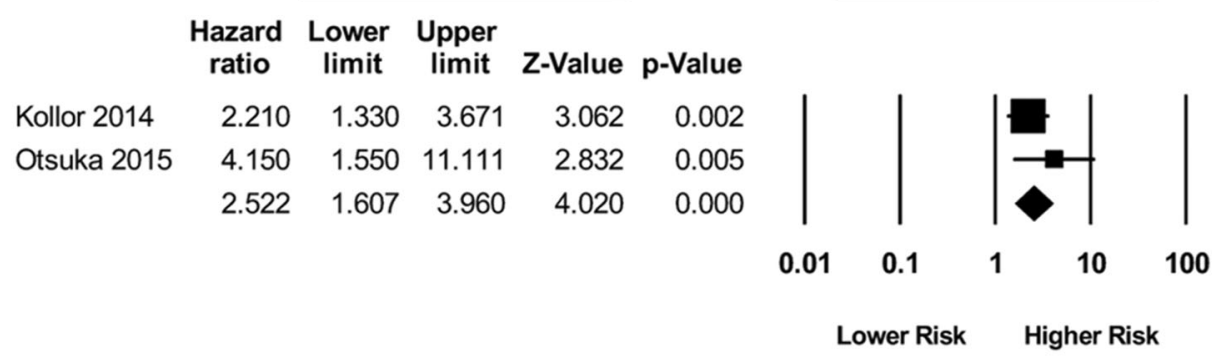

b) High CRP as a continuous variable and risk of cardiovascular mortality

\begin{tabular}{lccccrr} 
Study name & \multicolumn{5}{c}{ Statistics for each study } \\
\cline { 3 - 6 } & $\begin{array}{c}\text { Hazard } \\
\text { ratio }\end{array}$ & $\begin{array}{c}\text { Lower } \\
\text { limit }\end{array}$ & $\begin{array}{c}\text { Upper } \\
\text { limit }\end{array}$ & Z-Value & p-Value \\
Kollor 2014 & 1.320 & 1.081 & 1.612 & 2.726 & 0.006 \\
Sugano 2018 & 1.050 & 0.760 & 1.450 & 0.296 & 0.767 \\
& 1.239 & 1.046 & 1.468 & 2.474 & 0.013
\end{tabular}

Hazard ratio and $95 \% \mathrm{Cl}$

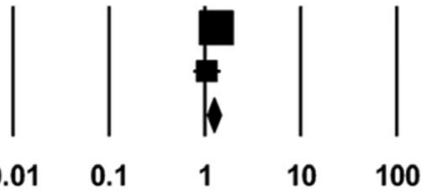

Lower Risk Higher Risk systemic pro-inflammatory hypothesis serves as a novel paradigm for the pathogenesis of HFpEF. Paulus et al. indicates that this systemic inflammatory state is induced by multiple underlying, synergistically acting comorbidities, many of which were consistently present at baseline in most of the HFpEF cohorts included in this meta-analysis, such as obesity,
Fig. 4 High CRP as a a categorical variable and risk of cardiovascular outcomes; as a b continuous variable and risk of cardiovascular outcomes

\section{a) High CRP as a categorical variable and risk of cardiovascular outcomes}

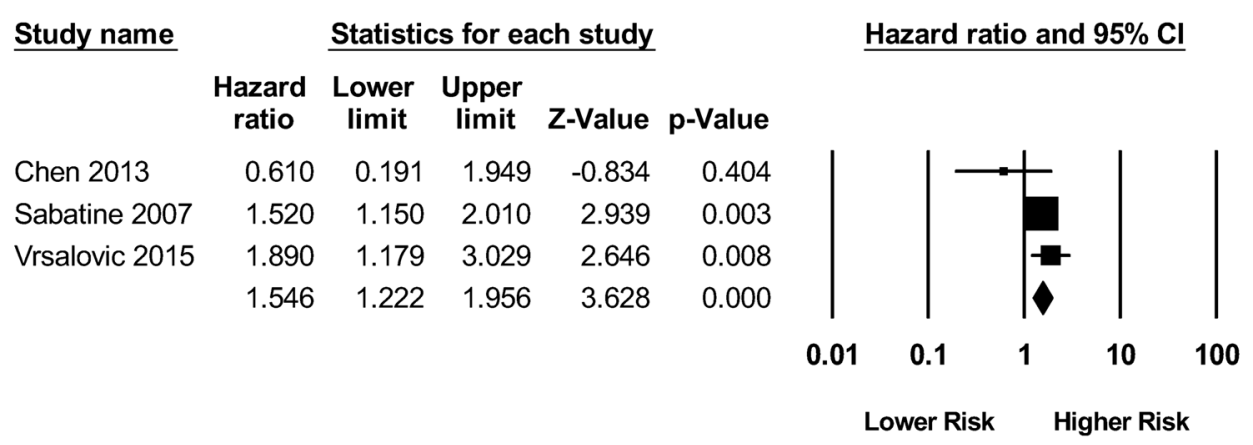

b) High CRP as a continuous variable and risk of cardiovascular outcomes

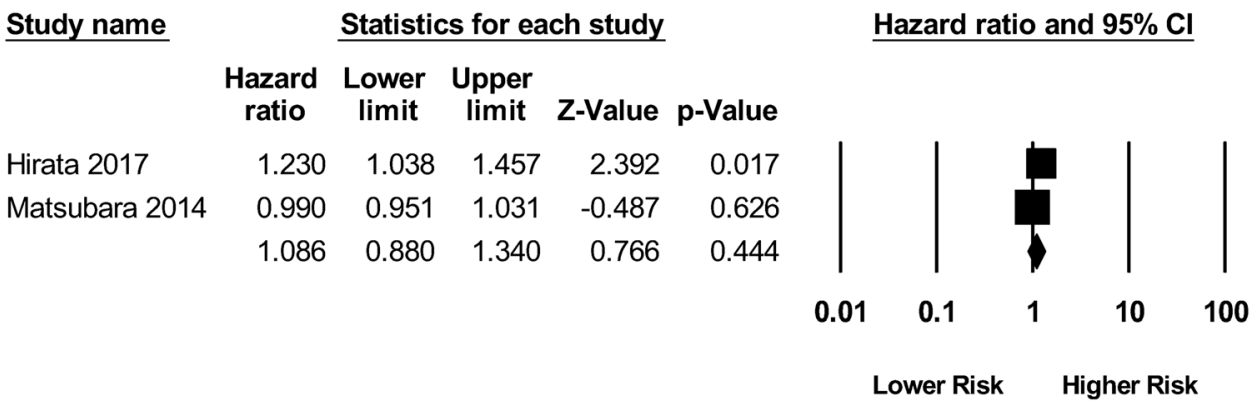


Fig. 5 High CRP as a a categorical variable and risk of all-cause mortality; as a b continuous variable and risk of all-cause mortality

\section{a) High CRP as a categorical variable and risk of all cause mortality}

Hazard ratio and $95 \% \mathrm{CI}$

\begin{tabular}{lccccc} 
Study name & \multicolumn{5}{c}{ Statistics for each study } \\
\cline { 2 - 6 } & $\begin{array}{c}\text { Hazard } \\
\text { ratio }\end{array}$ & $\begin{array}{c}\text { Lower } \\
\text { limit }\end{array}$ & $\begin{array}{c}\text { Upper } \\
\text { limit }\end{array}$ & Z-Value & p-Value \\
Aramburu-Bodas 2015 & 1.410 & 0.770 & 2.581 & 1.114 & 0.265 \\
Kollor 2014 & 1.830 & 1.231 & 2.721 & 2.985 & 0.003 \\
Lourenco 2019 & 1.790 & 1.462 & 2.192 & 5.629 & 0.000 \\
Otsuka 2015 & 2.060 & 0.898 & 4.728 & 1.705 & 0.088 \\
Sabatine 2007 & 1.780 & 1.312 & 2.414 & 3.708 & 0.000 \\
& 1.776 & 1.531 & 2.059 & 7.601 & 0.000
\end{tabular}

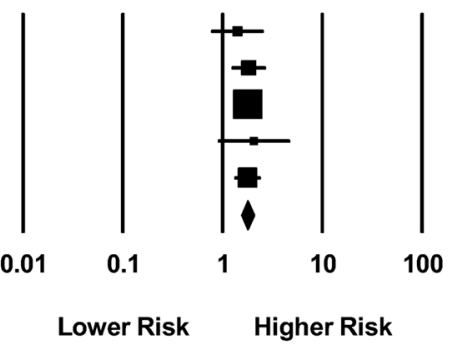

b) High CRP as a continuous variable and risk of all cause mortality

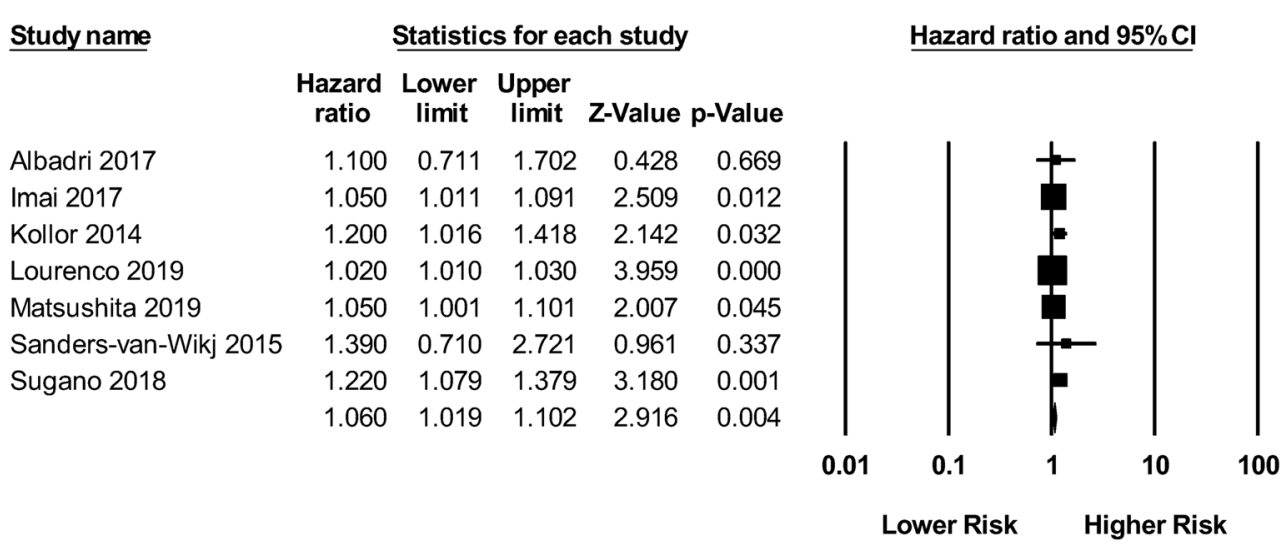

hypertension, diabetes mellitus (DM), and chronic obstructive pulmonary disease (COPD) [26]. This inflammation is characterized by a patterned elevation of cytokines and acute phase reactants, which collectively mediate the production of reactive oxygen species (ROS) from the coronary endothelium, thereby leading to a decrease in nitric oxide-cyclic guanosine monophosphate (NO-cGMP) signaling in the adjacent myocardium. It should be noted that CRP not only contributes to a reduction in coronary endothelial NO bioavailability by this mechanism but also likely through its direct downregulation of endothelial nitric oxide synthase [27]. All in all, impairment of the NO-cGMP pathway in turn leads to collagen deposition, left ventricular remodeling, and subsequent diastolic dysfunction [26].

Although there is paucity in literature discussing the role of CRP in HFpEF, CRP has long known to be correlated with a higher incidence of cardiac events in patients with existing cardiovascular disease (CVD). CRP can be synthesized by both hepatic and extrahepatic tissues with the rate of its production conditioned on the severity of the underlying pathological condition [28], making it a sensitive marker for risk assessment [29]. Nonetheless, despite the demonstrated predictive value of baseline CRP in CVD [30,31], problems exist with its use primarily due to its lack of specificity. Furthermore, currently in clinical practice, serum CRP concentrations are traditionally categorized into three tertiles: (i) $<1 \mathrm{mg} / \mathrm{l}$, (ii) $1-3 \mathrm{mg} / \mathrm{l}$, and (iii) $>3 \mathrm{mg} / \mathrm{l}$, wherein tertile two and tertile three are associated with a $50 \%$ and $100 \%$ greater cardiovascular risk than tertile one, respectively [32]. However, in an observational study showcasing the effect of population characteristics on CRP, Werner et al. illustrates that age, sex, and ethnicity can all impact serum CRP concentrations. This influence of patient demographics potentially accounts for the various, distinct CRP cutoffs present in the studies included in this meta-analysis, and in turn lends credence to the notion that cutoffs adjusted for baseline factors are needed in order to achieve adequate risk stratification in the clinical setting [33].

\section{Limitations}

There are several limitations for this systematic review and meta-analysis that should be noted. Firstly, this is a studylevel meta-analysis in contrast to a data-level meta-analysis, which could improve the accuracy of our findings. Secondly, significant heterogeneity $\left(I^{2}>50\right)$ was observed with certain 
effect sizes. This may be due to the differences in the characteristics of the study populations, study design, CRP cutoff values or intervals, blood sampling time, and CRP measurement method (as serum hsCRP or CRP). Thirdly, as a marker for systemic inflammation, it is clearly evident that serum CRP concentrations can be affected by many diseases other than HFpEF that also predispose to a pro-inflammatory state. Some studies consisted of patients with HFpEF that developed as sequelae to such underlying inflammatory conditions including but not limited to coronary artery disease, peripheral vascular disease, end-stage renal disease, and hypertensive heart disease. In these cases, it is difficult to determine whether the elevation of CRP in these subjects is due to the independent effect of the disease itself, the HFpEF phenotype, or most likely, a combination of both. As such, the presence of coexisting diseases may have not only skewed the overall effect sizes but also, in light of its aforementioned lack of specificity, CRP will likely only be useful as an accessorial form of guidance in the clinical management of HFpEF patients, as opposed to a forerunning parameter used as the basis of risk stratification. Fourthly, it must be noted that there is likely an association between CRP and the severity of HFpEF because, as aforementioned, the degree of elevation in serum CRP concentration is related to the extent of the underlying inflammatory condition. As a result, the relationship between CRP and clinical outcomes may simply reflect a relationship between HFpEF severity and clinical outcomes. If CRP is merely a surrogate for HFpEF severity, then it is likely that CRP is a marker, rather than a predictor, for outcomes in HFpEF.

\section{Conclusions}

The findings of this systematic review and meta-analysis indicate that CRP could be used as a biomarker that not only predicts the development of new onset HFpEF but also clinical outcomes following HFpEF in the long run. However, it should be noted that the present study possesses all the traditional limitations that typically accompany meta-analyses, and as such, readers should consider the fact that the reported diagnostic and prognostic potential of CRP in HFpEF is only accurate if said limitations are of no relevance. As a result, given the inherent methodological restrictions of this analysis, further prospective studies are still needed to not only explore the utility and dynamicity of CRP in HFpEF but also to determine whether risk stratification algorithms incorporating CRP actually provide a material benefit in bettering long-term outcomes. All in all, obtaining a greater understanding of CRP in the context of HFpEF through a consistent, repetitive demonstration of such findings in the in future prospective investigations, new treatment strategies can be devised and patient guidance can accordingly be enhanced to improve overall prognosis.

Open Access This article is licensed under a Creative Commons Attribution 4.0 International License, which permits use, sharing, adaptation, distribution and reproduction in any medium or format, as long as you give appropriate credit to the original author(s) and the source, provide a link to the Creative Commons licence, and indicate if changes were made. The images or other third party material in this article are included in the article's Creative Commons licence, unless indicated otherwise in a credit line to the material. If material is not included in the article's Creative Commons licence and your intended use is not permitted by statutory regulation or exceeds the permitted use, you will need to obtain permission directly from the copyright holder. To view a copy of this licence, visit http://creativecommons.org/licenses/by/4.0/.

\section{References}

1. Ponikowski P, Voors AA, Anker SD, Bueno H, Cleland JG, Coats AJ, Falk V, González-Juanatey JR, Harjola VP, Jankowska EA, Jessup M, Linde C, Nihoyannopoulos P, Parissis JT, Pieske B, Riley JP, Rosano GM, Ruilope LM, Ruschitzka F, Rutten FH, van der Meer P, Members ATF, Reviewers D (2016) 2016 ESC Guidelines for the diagnosis and treatment of acute and chronic heart failure: the Task Force for the diagnosis and treatment of acute and chronic heart failure of the European Society of Cardiology (ESC). Developed with the special contribution of the Heart Failure Association (HFA) of the ESC. Eur J Heart Fail 18(8): 891-975. https://doi.org/10.1002/ejhf.592

2. Abernethy A, Raza S, Sun JL, Anstrom KJ, Tracy R, Steiner J, VanBuren P, LeWinter MM (2018) Pro-inflammatory biomarkers in stable versus acutely decompensated heart failure with preserved ejection fraction. J Am Heart Assoc 7(8). https://doi.org/10.1161/ JAHA.117.007385

3. van Wezenbeek J, Canada JM, Ravindra K, Carbone S, Trankle CR, Kadariya D, Buckley LF, Del Buono M, Billingsley H, Viscusi M, Wohlford GF, Arena R, Van Tassell B, Abbate A (2018) C-reactive protein and $\mathrm{N}$-terminal pro-brain natriuretic peptide levels correlate with impaired cardiorespiratory fitness in patients with heart failure across a wide range of ejection fraction. Front Cardiovasc Med 5: 178. https://doi.org/10.3389/fcvm.2018.00178

4. Moher D, Shamseer L, Clarke M, Ghersi D, Liberati A, Petticrew M, Shekelle P, Stewart LA, Group P-P (2015) Preferred reporting items for systematic review and meta-analysis protocols (PRISMAP) 2015 statement. Syst Rev 4:1. https://doi.org/10.1186/20464053-4-1

5. Brouwers FP, van Gilst WH, Damman K, van den Berg MP, Gansevoort RT, Bakker SJ, Hillege HL, van Veldhuisen DJ, van der Harst P, de Boer RA (2014) Clinical risk stratification optimizes value of biomarkers to predict new-onset heart failure in a community-based cohort. Circ Heart Fail 7(5):723-731. https:// doi.org/10.1161/CIRCHEARTFAILURE.114.001185

6. de Boer RA, Nayor M, deFilippi CR, Enserro D, Bhambhani V, Kizer JR, Blaha MJ, Brouwers FP, Cushman M, Lima JAC, Bahrami H, van der Harst P, Wang TJ, Gansevoort RT, Fox CS, Gaggin HK, Kop WJ, Liu K, Vasan RS, Psaty BM, Lee DS, Hillege HL, Bartz TM, Benjamin EJ, Chan C, Allison M, Gardin JM, Januzzi JL, Shah SJ, Levy D, Herrington DM, Larson MG, van Gilst WH, Gottdiener JS, Bertoni AG, Ho JE (2018) Association of cardiovascular biomarkers with incident heart failure with 
preserved and reduced ejection fraction. JAMA Cardiol 3(3):215224. https://doi.org/10.1001/jamacardio.2017.4987

7. Kalogeropoulos A, Georgiopoulou V, Psaty BM, Rodondi N, Smith AL, Harrison DG, Liu Y, Hoffmann U, Bauer DC, Newman AB, Kritchevsky SB, Harris TB, Butler J, Investigators HAS (2010) Inflammatory markers and incident heart failure risk in older adults: the Health $\mathrm{ABC}$ (Health, Aging, and Body Composition) study. J Am Coll Cardiol 55(19):2129-2137. https://doi.org/10.1016/j.jacc. 2009.12.045

8. Silverman MG, Patel B, Blankstein R, Lima JA, Blumenthal RS, Nasir K, Blaha MJ (2016) Impact of race, ethnicity, and multimodality biomarkers on the incidence of new-onset heart failure with preserved ejection fraction (from the Multi-Ethnic Study of Atherosclerosis). Am J Cardiol 117(9):1474-1481. https://doi.org/ 10.1016/j.amjcard.2016.02.017

9. Tromp J, Khan MA, Klip IT, Meyer S, de Boer RA, Jaarsma T, Hillege H, van Veldhuisen DJ, van der Meer P, Voors AA (2017) Biomarker profiles in heart failure patients with preserved and reduced ejection fraction. J Am Heart Assoc 6(4). https://doi.org/10. 1161/JAHA.116.003989

10. Koller L, Kleber M, Goliasch G, Sulzgruber P, Scharnagl H, Silbernagel G, Grammer T, Delgado G, Tomaschitz A, Pilz S, März W, Niessner A (2014) C-reactive protein predicts mortality in patients referred for coronary angiography and symptoms of heart failure with preserved ejection fraction. Eur J Heart Fail 16(7):758-766. https://doi.org/10.1002/ejhf.104

11. Otsuka K, Nakanishi K, Shimada K, Nakamura H, Inanami H, Nishioka H, Fujimoto K, Kasayuki N, Yoshiyama M (2018) Associations of sensitive cardiac troponin-I with left ventricular morphology, function and prognosis in end-stage renal disease patients with preserved ejection fraction. Heart Vessel 33(11):1334 1342. https://doi.org/10.1007/s00380-018-1192-7

12. Sugano A, Seo Y, Ishizu T, Sai S, Yamamoto M, Hamada-Harimura Y, Machino-Ohtsuka T, Obara K, Nishi I, Aonuma K, Nogami A (2019) Soluble ST2 and brain natriuretic peptide predict different mode of death in patients with heart failure and preserved ejection fraction. J Cardiol 73(4):326-332. https://doi.org/10.1016/j.jjcc. 2018.10.012

13. Chen WS, Chen SJ, Lee CC, Cherng WJ, Liu MH, Wang CH (2013) Plasma P-selectin predicts long-term cardiovascular events in hospitalized patients with suspected coronary artery disease and preserved left ventricular function: a 10-year follow-up study. Biom J 36(3):137-143. https://doi.org/10.4103/2319-4170.113231

14. Sabatine MS, Morrow DA, Jablonski KA, Rice MM, Warnica JW, Domanski MJ, Hsia J, Gersh BJ, Rifai N, Ridker PM, Pfeffer MA, Braunwald E, Investigators P (2007) Prognostic significance of the Centers for Disease Control/American Heart Association highsensitivity C-reactive protein cut points for cardiovascular and other outcomes in patients with stable coronary artery disease. Circulation 115(12):1528-1536. https://doi.org/10.1161/ CIRCULATIONAHA.106.649939

15. Vrsalović M, Vučur K, Car B, Krčmar T, Vrsalović Presečki A (2015) C-reactive protein, renal function, and cardiovascular outcome in patients with symptomatic peripheral artery disease and preserved left ventricular systolic function. Croat Med J 56(4): 351-356. https://doi.org/10.3325/cmj.2015.56.351

16. Hirata Y, Yamamoto E, Tokitsu T, Kusaka H, Fujisue K, Kurokawa H, Sugamura K, Maeda H, Tsujita K, Yamamuro M, Kaikita K, Hokimoto S, Sugiyama S, Ogawa H (2015) Reactive oxidative metabolites are associated with the severity of heart failure and predict future cardiovascular events in heart failure with preserved left ventricular ejection fraction. Int J Cardiol 179:305-308. https:// doi.org/10.1016/j.ijcard.2014.11.018

17. Matsubara J, Sugiyama S, Nozaki T, Akiyama E, Matsuzawa Y, Kurokawa H, Maeda H, Fujisue K, Sugamura K, Yamamoto E, Matsui K, Jinnouchi H, Ogawa H (2014) Incremental prognostic significance of the elevated levels of pentraxin 3 in patients with heart failure with normal left ventricular ejection fraction. J Am Heart Assoc 3(4). https://doi.org/10.1161/JAHA.114.000928

18. Aramburu-Bodas Ó, García-Casado B, Salamanca-Bautista P, Guisado-Espartero ME, Arias-Jiménez JL, Barco-Sánchez A, Santamaría-González JC, Formiga F, Montero-Pérez-Barquero M, Manzano L (2015) Relationship between osteoprotegerin and mortality in decompensated heart failure with preserved ejection fraction. J Cardiovasc Med (Hagerstown) 16(6):438-443. https://doi. org/10.2459/JCM.0000000000000229

19. Lourenço P, Pereira J, Ribeiro A, Ferreira-Coimbra J, Barroso I, Guimarães JT, Leite-Moreira A, Bettencourt P (2019) C-reactive protein decrease associates with mortality reduction only in heart failure with preserved ejection fraction. J Cardiovasc Med (Hagerstown) 20(1):23-29. https://doi.org/10.2459/JCM. 0000000000000726

20. AlBadri A, Lai K, Wei J, Landes S, Mehta PK, Li Q, Johnson D, Reis SE, Kelsey SF, Bittner V, Sopko G, Shaw LJ, Pepine CJ, Bairey Merz CN (2017) Inflammatory biomarkers as predictors of heart failure in women without obstructive coronary artery disease: a report from the NHLBI-sponsored Women's Ischemia Syndrome Evaluation (WISE). PLoS One 12(5):e0177684. https://doi.org/10. 1371/journal.pone. 0177684

21. Imai R, Uemura Y, Okumura T, Takemoto K, Uchikawa T, Koyasu M, Ishikawa S, Iwamiya S, Ozaki Y, Shibata R, Watarai M, Murohara T (2017) Impact of red blood cell distribution width on non-cardiac mortality in patients with acute decompensated heart failure with preserved ejection fraction. J Cardiol 70(6):591-597. https://doi.org/10.1016/j.jjcc.2017.03.010

22. Matsushita K, Harada K, Miyazaki T, Miyamoto T, Kohsaka S, Iida K, Tanimoto S, Takei M, Hosoda T, Yamamoto Y, Shiraishi Y, Yoshino H, Yamamoto T, Nagao K, Takayama M (2019) Different prognostic associations of beta-blockers and diuretics in heart failure with preserved ejection fraction with versus without high blood pressure. J Hypertens 37(3):643-649. https://doi.org/10. 1097/HJH.0000000000001932

23. Sanders-van Wijk S, van Empel V, Davarzani N, Maeder MT, Handschin R, Pfisterer ME, Brunner-La Rocca HP, investigators T-C (2015) Circulating biomarkers of distinct pathophysiological pathways in heart failure with preserved vs. reduced left ventricular ejection fraction. Eur J Heart Fail 17 (10):1006-1014. doi:https:// doi.org/10.1002/ejhf.414

24. Ge Z, Li A, McNamara J, Dos Remedios C, Lal S (2019) Pathogenesis and pathophysiology of heart failure with reduced ejection fraction: translation to human studies. Heart Fail Rev. https://doi.org/10.1007/s10741-019-09806-0

25. Lakhani I, Leung KSK, Tse G, Lee APW (2019) Novel mechanisms in heart failure with preserved, midrange, and reduced ejection fraction. Front Physiol 10:874. https://doi.org/10.3389/fphys. 2019.00874

26. Paulus WJ, Tschöpe C (2013) A novel paradigm for heart failure with preserved ejection fraction: comorbidities drive myocardial dysfunction and remodeling through coronary microvascular endothelial inflammation. J Am Coll Cardiol 62(4):263-271. https://doi. org/10.1016/j.jacc.2013.02.092

27. Singh U, Devaraj S, Vasquez-Vivar J, Jialal I (2007) C-reactive protein decreases endothelial nitric oxide synthase activity via uncoupling. J Mol Cell Cardiol 43(6):780-791. https://doi.org/10. 1016/j.yjmcc.2007.08.015

28. Adukauskienė D, Čiginskienė A, Adukauskaitė A, Pentiokinienė D, Šlapikas R, Čeponienė I (2016) Clinical relevance of high sensitivity C-reactive protein in cardiology. Medicina (Kaunas) 52(1): 1-10. https://doi.org/10.1016/j.medici.2015.12.001

29. Greenland P, Alpert JS, Beller GA, Benjamin EJ, Budoff MJ, Fayad ZA, Foster E, Hlatky MA, Hodgson JM, Kushner FG, Lauer MS, Shaw LJ, Smith SC, Taylor AJ, Weintraub WS, Wenger NK, Jacobs 
AK, Anderson JL, Albert N, Buller CE, Creager MA, Ettinger SM, Guyton RA, Halperin JL, Hochman JS, Nishimura R, Ohman EM, Page RL, Stevenson WG, Tarkington LG, Yancy CW, Foundation ACoC, Association AH (2010) 2010 ACCF/AHA guideline for assessment of cardiovascular risk in asymptomatic adults: a report of the American College of Cardiology Foundation/American Heart Association Task Force on Practice Guidelines. J Am Coll Cardiol 56(25):e50-e103. https://doi.org/10.1016/j.jacc.2010.09. 001

30. Silva D, Pais de Lacerda A (2012) High-sensitivity C-reactive protein as a biomarker of risk in coronary artery disease. Rev Port Cardiol 31(11):733-745. https://doi.org/10.1016/j.repc.2012.02. 018

31. Ridker PM, Glynn RJ, Hennekens CH (1998) C-reactive protein adds to the predictive value of total and HDL cholesterol in determining risk of first myocardial infarction. Circulation 97(20): 2007-2011. https://doi.org/10.1161/01.cir.97.20.2007

32. Salazar J, Martínez MS, Chávez M, Toledo A, Añez R, Torres Y, Apruzzese V, Silva C, Rojas J, Bermúdez V (2014) C-reactive protein: clinical and epidemiological perspectives. Cardiol Res Pract 2014:605810. https://doi.org/10.1155/2014/605810

33. Wener MH, Daum PR, McQuillan GM (2000) The influence of age, sex, and race on the upper reference limit of serum C-reactive protein concentration. J Rheumatol 27(10):2351-2359

Publisher's note Springer Nature remains neutral with regard to jurisdictional claims in published maps and institutional affiliations. 